\title{
Reproducibility of fundus autofluorescence measurements obtained using a confocal scanning laser ophthalmoscope
}

\author{
Noemi Lois, Anthony S Halfyard, Catey Bunce, Alan C Bird, Fredrick W Fitzke
}

\begin{abstract}
Aim-To evaluate the reproducibility of the background fundus autofluorescence measurements obtained using a confocal scanning laser ophthalmoscope.

Methods-10 normal volunteers and 10 patients with retinal disease were included in the study. One eye per subject was chosen randomly. Five images of the same eye of each individual were obtained, after pupillary dilatation, by two investigators using a confocal scanning laser ophthalmoscope. Background fundus autofluorescence was measured at 7 degrees temporal to the fovea in normal volunteers and between 7 and 15 degrees temporal to the fovea in patients. Within session reproducibility of the measurements obtained by each investigator and interobserver reproducibility were evaluated.
\end{abstract}

Results-For investigator 1 the median values of fundus autofluorescence obtained were 31.9 units for normal volunteers and 27.3 units for patients. The median largest difference in readings in normal volunteers was 5.7 units (range 1.4-13.5 units) and in patients 4.2 units (1.5-15.1 units). For investigator 2 the median values of fundus autofluorescence obtained were 28.9 units for normal volunteers and 27.4 units for patients. The median largest difference in readings in normal volunteers was 3.6 units $(2.7-11.7$ units), and in patients 4.1 units (1.5-9.3 units). The median interobserver difference in readings in normal volunteers was 3.3 units and for patients 6.6 units. The median greatest interobserver difference in measurements obtained for normal volunteers was 8.8 units (8.4-23.0 units) and for patients 11.1 units (7.1-40.8 units). Conclusion-Within session reproducibility of the measurements of background fundus autofluorescence was satisfactory. Although interobserver reproducibility was moderate, the variability of the measurements of fundus autofluorescence between observers appears to be small when compared with variation in fundus autofluorescence with age and disease. (Br f Ophthalmol 1999;83:276-279)

It is well recognised that lipofuscin accumulates in the retinal pigment epithelium (RPE) with age. ${ }^{1-5}$ Similarly, is has been demonstrated that the RPE contains abnormally high levels of lipofuscin in a number of inherited retinal disorders, such as Best's disease and Stargardt fundus flavimaculatus, ${ }^{6-11}$ and it is likely to be a crucial event in the development of age related macular degeneration. ${ }^{12-14}$ Thus, the study of the lipofuscin content in the RPE may give us more insight into the pathogenesis of a number of retinal diseases.

In recent years it has become possible to detect and image fundus autofluorescence in the living eye as an index of lipofuscin accumulation in the RPE. ${ }^{15-17}$ Using a confocal scanning laser ophthalmoscope, characteristic patterns of fundus autofluorescence in normal subjects and in patients with different retinal disorders have been described. ${ }^{15} 1819$ Similarly, autofluorescence measurements can be obtained by this method. ${ }^{18}$ Although values of fundus autofluorescence appear to be objective, their reproducibility remains to be established.

The purpose of the present study was to evaluate the reproducibility of fundus autofluorescence measurements obtained with a confocal scanning laser ophthalmoscope.

\section{Subjects and methods}

Ten normal volunteers (seven men and three women) and 10 patients with retinal disease (three men and seven women) were included in the study. The median age of normal volunteers was 33 years (range 25-40 years), and of patients 56 years (14-74 years). All normal volunteers had clear lenses and no abnormalities on fundus examination. In patients the lens was clear or showed mild nuclear sclerosis on slit lamp biomicroscopy. Retinal diseases included age related macular degeneration (four eyes), Stargardt-Fundus flavimaculatus (two eyes), bull's eye macular dystrophy (two eyes), dominant drusen (one eye), and cone dystrophy (one eye).

One eye per subject was chosen randomly. Images were taken after pupillary dilatation with tropicamide $1 \%$ and phenylephrine $2.5 \%$. The mean pupillary size before imaging was $7.1 \mathrm{~mm}$ in normal volunteers (range 6.5-8 $\mathrm{mm}$ ) and $6.4 \mathrm{~mm}$ in patients $(5-8 \mathrm{~mm})$.

Fundus autofluorescent images were obtained using a confocal scanning laser ophthalmoscope (cSLO, Zeiss, Oberkochen, Germany) as previously described. ${ }^{18}$ Briefly, autofluorescent images were produced using a 40 degree field of view mode, and a confocal aperture which provided a full width half maximum depth resolution of less than $600 \mu \mathrm{m}$. The ametropic corrector was employed to correct for refractive error and to focus on the structure of interest. An argon laser light (488
Accepted for publication 23 October 1998 
$\mathrm{nm}, 250 \mu \mathrm{W}$ ) was used for illumination, and a wide band pass filter with short wavelength cut off of $521 \mathrm{~nm}$ was inserted in front of the detector to record fundus autofluorescence. The instrument gain was kept constant for all subjects/patients.

A series of images of each eye was recorded, in the same visit, at standard video scanning rates on SVHS video tape. Later, 32 consecutive frames were digitised, aligned, and averaged, followed by another 32 frames and so on, until five sets of 32 frames were processed. The result of each 32 digitised, aligned, and averaged frames was a single image. Thus, five images per eye examined were obtained.

The intensity of autofluorescence was measured in grey scale arbitrary units in the five images obtained for each subject/patient. The intensity of autofluorescence was calculated by subtracting the background grey scale intensity (lowest intensity measured over the optic nerve head) from the average intensity of

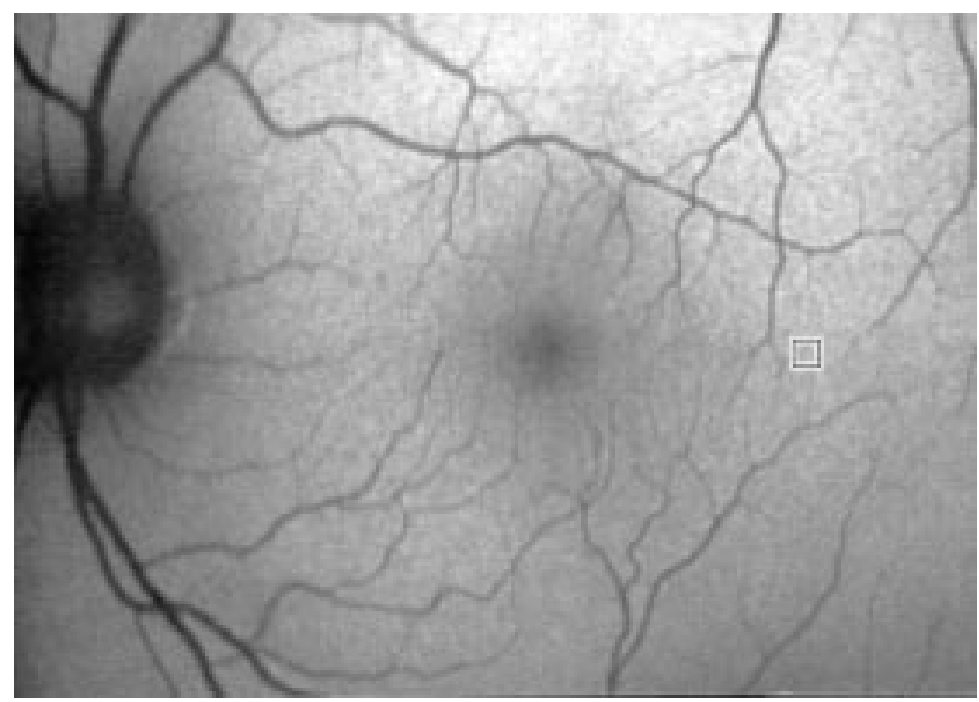

Figure 1 Image of fundus autofluorescence of a normal volunteer. A $16 \times 16$ pixel box is observed over the area of interest, 7 degrees temporally to the fovea.

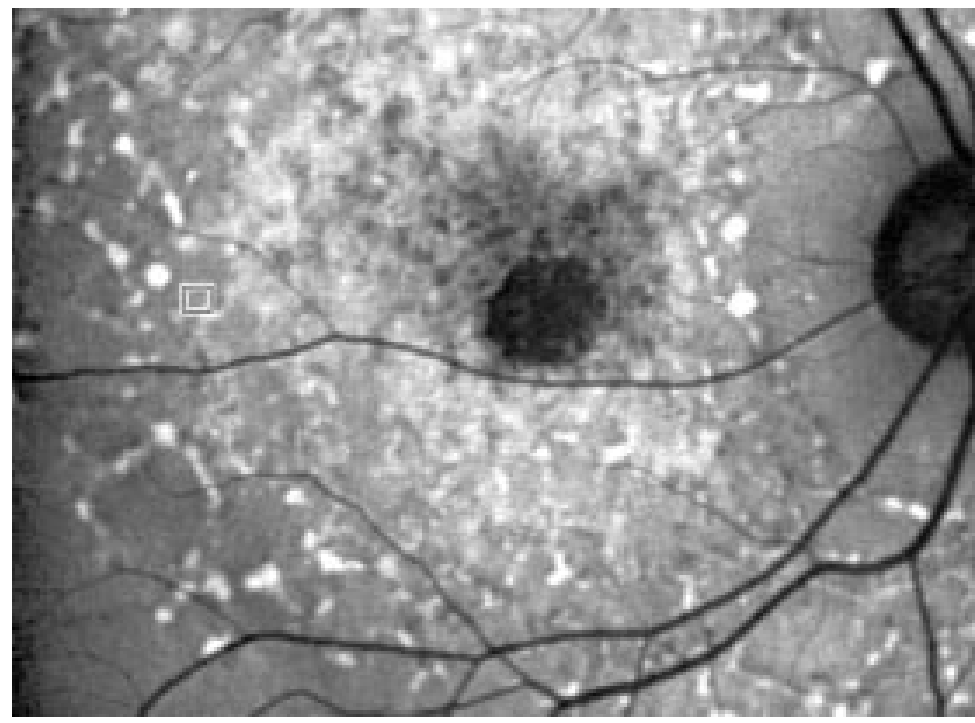

Figure 2 Image of fundus autofluorescence of a patient with fundus flavimaculatus. A 16 $\times 16$ pixel box is observed over the area of interest, between 7 and 15 degrees temporally to the fovea, where no local changes of fundus autofluorescence were seen. an $16 \times 16$ pixel box over the area of interest. In normal volunteers, the $16 \times 16$ pixel box, used as the area of analysis, was centred 7 degrees temporal to the fovea (Fig 1). In patients, the $16 \times 16$ pixel box was centred between 7 and 15 degrees temporal to the fovea, where no local changes in fundus autofluorescence were seen (Fig 2).

Images were taken, processed, and measured by two investigators (NL and $\mathrm{ASH}$ ) in an independent manner. The subject/patient was repositioned in the cSLO between observers.

Within session reproducibility of the measurements obtained by each investigator, and interobserver reproducibility were evaluated. Within session variability was assessed by evaluating the median largest difference in readings (highest minus lowest value of the five readings taken) for normal volunteers and patients obtained by each investigator. Interobserver reproducibility was estimated by comparing the readings obtained from the first image of each subject/patient by investigator 1 and investigator 2 . In addition, the greatest differences in readings between observers was calculated (highest value of the five measurements obtained by investigator 1 minus lowest value of the five measurements obtained by investigator 2, and vice versa, for each subject/ patient).

\section{Results}

For investigator 1 the median values of fundus autofluorescence obtained were 31.9 units for normal volunteers and 27.3 units for patients. The median largest difference in readings in normal volunteers was 5.7 units (range 1.413.5 units), and in patients 4.2 units (1.5-15.1 units) (Tables 1 and 2, Fig 3). For investigator 2 the median values of fundus autofluorescence obtained were 28.9 units for normal volunteers and 27.4 units for patients. The median largest difference in readings in normal volunteers was 3.6 units (2.7-11.7 units), and in patients 4.1 units (1.5-9.3 units) (Tables 1 and 2, Fig 3). The median difference in readings obtained between observers for normal volunteers was 3.3 units and for patients 6.6 units (Table 3 ). The median greatest interobserver difference in measurements obtained for normal volunteers was 8.8 units (8.4-23.0 units) (Table 4), and for patients 11.1 units (7.1-40.8 units) (Table 5).

\section{Discussion}

The possibility of studying in vivo lipofuscin accumulation in the RPE, either by using a spectrophotometer $^{161720}$ or a confocal scanning laser ophthalmoscope, ${ }^{15} 1819$ represents a step forward in recording the fundus changes with age and disease. It is hoped that this may provide a greater understanding of the pathogenetic mechanisms of retinal disease. There is clear value in recording the distribution of autofluorescence. By this method, local changes of fundus autofluorescence over time, which may be decisive in the development of a number of retinal diseases such as age related macular degeneration, can be detected. Measurements of background fundus autofluores- 
Table 1 Median of values of fundus autofluorescence and largest differences in readings (highest - lowest) obtained, in normal volunteers, by investigator 1 and 2

\begin{tabular}{|c|c|c|c|c|c|c|c|}
\hline \multicolumn{4}{|c|}{ Investigator 1} & \multicolumn{4}{|c|}{ Investigator 2} \\
\hline Volunteer & $\begin{array}{l}\text { Age } \\
\text { (years) }\end{array}$ & $\begin{array}{l}\text { Median } \\
\text { (arbitrary } \\
\text { units) }\end{array}$ & $\begin{array}{l}\text { Largest } \\
\text { difference in } \\
\text { readings } \\
\text { (arbitrary } \\
\text { units) }\end{array}$ & Volunteer & $\begin{array}{l}\text { Age } \\
\text { (years) }\end{array}$ & $\begin{array}{l}\text { Median } \\
\text { (arbitrary } \\
\text { units) }\end{array}$ & $\begin{array}{l}\text { Largest } \\
\text { difference in } \\
\text { readings } \\
\text { (arbitrary } \\
\text { units) }\end{array}$ \\
\hline 1 & 32 & 25.04 & 1.4 & 1 & 32 & 29.81 & 4.3 \\
\hline 2 & 34 & 17.63 & 5.2 & 2 & 34 & 20.50 & 4.7 \\
\hline 3 & 32 & 15.89 & 5.1 & 3 & 32 & 19.09 & 7.6 \\
\hline 4 & 40 & 33.86 & 7.6 & 4 & 40 & 43.91 & 3.0 \\
\hline 5 & 25 & 30.01 & 6.3 & 5 & 25 & 26.13 & 2.7 \\
\hline 6 & 34 & 38.32 & 4.0 & 6 & 34 & 34.62 & 3.0 \\
\hline 7 & 29 & 36.15 & 6.9 & 7 & 29 & 21.59 & 5.1 \\
\hline 8 & 32 & 26.74 & 3.9 & 8 & 32 & 28.92 & 2.7 \\
\hline 9 & 38 & 38.30 & 6.3 & 9 & 38 & 29.95 & 3.0 \\
\hline 10 & 40 & 35.78 & 13.5 & 10 & 40 & 28.89 & 11.7 \\
\hline Median & 33 & 31.93 & 5.75 & Median & 33 & 28.90 & 3.65 \\
\hline
\end{tabular}

Table 2 Median of values of fundus autofluorescence and largest differences in readings (highest - lowest) obtained, in patients, by investigator 1 and 2

\begin{tabular}{|c|c|c|c|c|c|c|c|}
\hline \multicolumn{4}{|c|}{ Investigator 1} & \multicolumn{4}{|c|}{ Investigator 2} \\
\hline Patient & $\begin{array}{l}\text { Age } \\
\text { (years) }\end{array}$ & $\begin{array}{l}\text { Median } \\
\text { (arbitrary } \\
\text { units) }\end{array}$ & $\begin{array}{l}\text { Largest } \\
\text { difference in } \\
\text { readings } \\
\text { (arbitrary } \\
\text { units) }\end{array}$ & Patient & $\begin{array}{l}\text { Age } \\
\text { (years) }\end{array}$ & $\begin{array}{l}\text { Median } \\
\text { (arbitrary } \\
\text { units) }\end{array}$ & $\begin{array}{l}\text { Largest } \\
\text { difference in } \\
\text { readings } \\
\text { (arbitrary } \\
\text { units) }\end{array}$ \\
\hline 1 & 62 & 21.48 & 3.2 & 1 & 62 & 25.66 & 2.2 \\
\hline 2 & 22 & 66.03 & 9.3 & 2 & 22 & 95.32 & 7.2 \\
\hline 3 & 71 & 25.48 & 1.5 & 3 & 71 & 30.78 & 3.0 \\
\hline 4 & 72 & 28.74 & 3.8 & 4 & 72 & 21.16 & 8.7 \\
\hline 5 & 41 & 28.55 & 7.2 & 5 & 41 & 40.80 & 4.0 \\
\hline 6 & 51 & 30.43 & 3.8 & 6 & 51 & 26.62 & 1.5 \\
\hline 7 & 65 & 43.76 & 5.8 & 7 & 65 & 45.00 & 9.3 \\
\hline 8 & 14 & 26.03 & 15.1 & 8 & 14 & 28.17 & 5.1 \\
\hline 9 & 17 & 18.28 & 1.5 & 9 & 17 & 11.22 & 3.1 \\
\hline 10 & 74 & 18.67 & 4.6 & 10 & 74 & 26.17 & 4.3 \\
\hline Median & 56.5 & 27.29 & 4.2 & Median & 56.5 & 27.39 & 4.1 \\
\hline
\end{tabular}

cence, if reliable and reproducible, might allow an early diagnosis in certain retinal disorders characterised by diffuse accumulation of lipofuscin in the RPE, such as Stargardt fundus flavimaculatus, when ophthalmoscopic features and functional loss are difficult to detect, ${ }^{11}$ and the recognition of carriers of the abnormal gene in retinal disease such as Best's disease. Furthermore, the detection of high levels of background fundus autofluorescence may be helpful when the differential diagnosis between pattern dystrophies and age related macular degeneration has to be established. Finally, recording the levels of autofluorescence with age may be important in detecting those at risk of visual loss and distinguishing the different phenotypes of age related macular degeneration.

Based on our results, it appears that individual examiners were internally reproducible when obtaining repeated measurements, indicating good within session reproducibility. However, when comparing the data obtained by both investigators, a higher variability in measurements was seen. A possible explanation for only moderate interobserver reproducibility is that the area selected by each examiner to measure fundus autofluorescence was not the same. Since values of fundus autofluorescence vary throughout the retina, ${ }^{17}{ }^{21}$ differences between investigators in the location of the pixel box at the time of the reading would produce different readings. This appears to be the case in eyes with retinal disease, in which each investigator selected the area of interest between 7 and 15 degrees temporally to the fovea, where no focal changes on autofluorescence were seen. Although no such variation would have been expected in normal volunteers, differences in localising the fovea would have influenced the readings obtained by both investigators.

Discrepancies between observers might be also related to difference in the quality of the images obtained. Several variables may have interfered unfavourably with the image acquisition increasing the interobserver variability. Thus, gross eye movement during the scanning period may have resulted in poor image alignment during the averaging process and, subsequently, in an inadequate final image. Similarly, mild lens opacities may have impaired the quality of the image by decreasing the signal to noise ratio. Other factors, such as small amounts of uncorrected refractive error

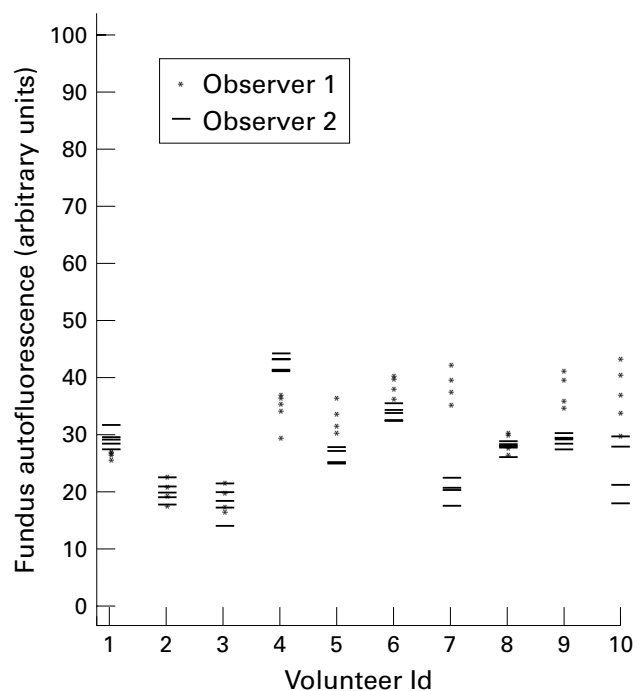

Figure 3 Scatter plot of the five values of fundus autofluorescence obtained for normal volunteers and patients by investigators 1 and 2 . 
Table 3 Difference in readings of fundus autofluorescence between the first image obtained by investigator 1 and the first image obtained from investigator 2 in normal volunteers and patients

\begin{tabular}{llll}
\hline Volunteer & $\begin{array}{l}\text { Difference in } \\
\text { readings between } \\
\text { investigators 1 and 2 } \\
\text { (arbitrary units) }\end{array}$ & Patient & $\begin{array}{l}\text { Difference in } \\
\text { readings between } \\
\text { investigators 1 and 2 } \\
\text { (arbitrary units) }\end{array}$ \\
\hline 1 & 5.0 & 1 & 3.9 \\
2 & 3.9 & 2 & 26.7 \\
3 & 0.1 & 3 & 7.1 \\
4 & 11.1 & 4 & 5.1 \\
5 & 2.7 & 5 & 14.0 \\
6 & 1.3 & 6 & 7.1 \\
7 & 22.4 & 7 & 1.7 \\
8 & 2.1 & 8 & 0.5 \\
9 & 10.5 & 9 & 8.7 \\
10 & 1.9 & 10 & 6.2 \\
Median & 3.3 & Median & 6.7 \\
\hline
\end{tabular}

Table 4 Greatest differences in fundus autofluorescence between observers for normal volunteers (largest- smallest absolute value)

\begin{tabular}{llll}
\hline & $\begin{array}{l}\text { HAF investigator } \\
1-L A F \\
\text { investigator 2 } \\
\text { (arbitrary units) }\end{array}$ & $\begin{array}{l}\text { HAF investigator } \\
\text { investigator 1 } \\
\text { (arbitrary units) }\end{array}$ & $\begin{array}{l}\text { Greatest } \\
\text { interobserver } \\
\text { variability } \\
\text { (arbitrary units) }\end{array}$ \\
\hline 1 & 2.67 & 8.40 & 8.40 \\
2 & 2.60 & 7.31 & 7.31 \\
3 & 5.24 & 7.43 & 7.43 \\
4 & 6.44 & 17.17 & 17.17 \\
5 & 9.27 & 0.20 & 9.27 \\
6 & 5.65 & 1.46 & 5.65 \\
7 & 22.42 & 10.35 & 22.42 \\
8 & 2.05 & 4.57 & 4.57 \\
9 & 11.41 & 2.15 & 11.41 \\
10 & 23.08 & 2.12 & 23.08 \\
Median & 6.04 & 5.94 & 8.83 \\
\hline
\end{tabular}

HAF investigator 1 - LAF investigator $2=$ highest value of fundus autofluorescence obtained by investigator 1 minus lowest value of fundus autofluorescence obtained by investigator 2 . $\mathrm{HAF}$ investigator $2-\mathrm{LAF}$ investigator 1 = highest value of fundus autofluorescence obtained by investigator 2 minus lowest value of fundus autofluorescence obtained by investigator 1 .

Table 5 Greatest differences in fundus autofluorescence measurements between observers for patients (largestsmallest absolute value)

\begin{tabular}{llll}
\hline & $\begin{array}{l}\text { HAF investigator } \\
1-L A F \\
\text { investigator 2 } \\
\text { (arbitrary units) }\end{array}$ & $\begin{array}{l}\text { HAF investigator } \\
2-L A F \\
\text { investigator 1 } \\
\text { (arbitrary units) }\end{array}$ & $\begin{array}{l}\text { Greatest } \\
\text { interobserver } \\
\text { variability } \\
\text { (arbitrary units) }\end{array}$ \\
\hline 1 & 2.03 & 7.50 & 7.50 \\
2 & 24.23 & 40.79 & 40.79 \\
3 & 2.65 & 7.11 & 7.11 \\
4 & 13.92 & 1.40 & 13.92 \\
5 & 4.23 & 15.5 & 15.50 \\
6 & 7.13 & 1.84 & 7.13 \\
7 & 6.10 & 9.10 & 9.10 \\
8 & 13.98 & 6.32 & 13.98 \\
9 & 9.69 & 5.01 & 9.69 \\
10 & 3.57 & 12.55 & 12.55 \\
Median & 6.61 & 7.30 & 11.12 \\
\hline
\end{tabular}

HAF investigator 1 - LAF investigator $2=$ highest value of fundus autofluorescence obtained by investigator 1 minus lowest value of fundus autofluorescence obtained by investigator 2 . $\mathrm{HAF}$ investigator $2-\mathrm{LAF}$ investigator $1=$ highest value of fundus autofluorescence obtained by investigator 2 minus lowest value of fundus autofluorescence obtained by investigator 1 .

and observer experience may have also influenced the results obtained.

Differences in readings between both investigators were high in some cases, especially when interobserver reproducibility was assessed by using the greatest difference in values obtained by both investigators (highest value of the five measurements obtained by investigator 1 minus the lowest value of the five measurements obtained by investigator 2 , and vice versa, for each subject). However, it should be pointed out that this way of analysis would reflect the highest variability that can occur. The reproducibility between observers may be improved by limiting observer participation in obtaining quantitative data, selecting only high quality images to measure fundus autofluorescence and, possibly, decreasing the number of reading areas per eye. Decreasing the image acquisition time may also decrease variability due to gross eye movement and may facilitate imaging subjects with poor fixation.

The potential value of this technique as used currently can be tested by comparing the variation in measurements of fundus autofluorescence obtained by different observers and that which occurs with age and retinal disease. It is evident that the latter is far larger than the former indicating that such measurements are useful in the study of disease.

Supported by the Macular Disease Society, United Kingdom (NL), and the Foundation Fighting Blindness, United States.

1 Feeney L. Lipofuscin and melanin of human retinal pigment epithelium. Fluorescence, enzyme cytochemical, and ultrastructural studies. Invest Ophthalmol Vis Sci 978;17:583-600

2 Feeney-Burns L, Berman ER, Rothman MS. Lipofuscin of human retinal pigment epithelium. Am f Ophthalmol 1980; 90:783-91.

3 Feeney-Burns L, Hilderbrand ES, Eldridge S. Aging human peripheral cells. Invest Ophthalmol Vis Sci 1984;25:195200.

4 Kitagawa K, Nishida S, Ogura Y. In vivo quantitation of autofluorescence in human retinal pigment epithelium. Ophthalmologica 1989;199:116-21.

5 Weiter JJ, Delori FC, Wing GL, et al. Retinal pigment epithelial lipofuscin and melanin and choroidal melanin in human eyes. Invest Ophthalmol Vis Sci 1986;27:145-52.

6 Weingeist TA, Kobrin JL, Watzke RC. Histopathology of Best's macular dystrophy. Arch Ophthalmol 1982;100: 1108-14.

7 Frangieh GT, Green WR, Fine SL. A histopathologic study of Best's macular dystrophy. Arch Ophthalmol 1982;100: 1115-21.

8 Eagle RC, Lucier AC, Bernardino VB, et al. Retinal pigment epithelial abnormalities in fundus flavimaculatus. A light and electron microscopic study. Ophthalmology 1980;87: $1189-200$.

9 Birnbach CD, Jõrvelõinen M, Possin DE, et al. Histopathology and immunocytochemistry of the neurosensory retina in fundus flavimaculatus. Ophthalmology 1994;101:1211-19.

10 Lopez PF, Maumenee IH, de la Cruz Z, et al. Autosomaldominant fundus flavimaculatus. Clinicopathologic correlation. Ophthalmology 1990;97:798-809.

11 Steinmetz RL, Garner A, Maguire JI, et al. Histopathology of incipient fundus flavimaculatus. Ophthalmology 1991;98: of incip

12 Dorey K, Staurenghi G, Delori FC. Lipofuscin in aged and ARMD eyes. In: Hollyfield JG, et al, eds. Retinal degeneration. New York: Plenum Press, 1993:3-14.

13 Feeney-Burns L, Ellersieck MR. Age-related changes in the ultrastructure of Bruch's membrane. Am $\mathcal{F}$ Ophthalmol 1985;100:686-97.

14 Dorey CK, Wu G, Ebenstein D, et al. Cell loss in the aging retina. Relationship to lipofuscin accumulation and macula

Von Rückmann A, Fitzke FW, Bird AC. Distribution of fundus autofluorescence with a scanning laser ophthalmodus autofluorescence with a scanning
scope. Br f Ophthalmol 1995;79:407-12.

16 Delori FC. Spectrophotometer for noninvasive measurements of intrinsic fluorescence and reflectance of the ocuments of intrinsic fluorescence and reflectance

17 Delori FC, Dorey CK, Staurenghi G, et al. In vivo fluorescence of the ocular fundus exhibits retinal pigment epithelium lipofuscin characteristics. Invest Ophthalmol Vis Sci 1995;36:718-29.

18 Von Rückmann A, Fitzke FW, Bird AC. In vivo fundus autofluorescence in macular dystrophies. Arch Ophthalmol 1997;115:609-15.

19 Von Rückmann A, Fitzke FW, Bird AC. Fundus autofluorescence in age-related macular disease with a laser scanning ophthalmoscope. Invest Ophthalmol Vis Sci 1997; 38:478-86.

20 Delori FC, Staurenghi G, Arend O, et al. In vivo measurement of lipofuscin in Stargardt's disease-fundus
flavimaculatus. Invest Ophthalmol Vis Sci 1995;36:2327-31.

21 Wing GL, Blanchard GC, Weiter JJ. The topography and age relationship of lipofuscin concentration in the retinal pigment epithelium. Invest Ophthalmol Vis Sci 1978;17: 601-7. 